\title{
Effect of age, sex, and refractive errors on central corneal thickness measured by Oculus Pentacam ${ }^{\circledR}$
}

This article was published in the following Dove Press journal:

Clinical Ophthalmology

30 June 2017

Number of times this article has been viewed

\author{
Nauman Hashmani' \\ Sharif Hashmani' \\ Azfar N Hanfi' \\ Misbah Ayub ${ }^{2}$ \\ Choudhry M Saad ${ }^{2}$ \\ Hina Rajani² \\ Marium G Muhammad ${ }^{2}$ \\ Misbahul Aziz' \\ 'Department of Ophthalmology, \\ Hashmanis Hospital, Karachi, Pakistan; \\ 2Dow Medical College, Karachi, \\ Pakistan
}

Background: Central corneal thickness (CCT) can be used to assess the corneal physiological condition as well as the pathological changes associated with ocular diseases. It has an influence on the measurement of intraocular pressure and is being used as a screening tool for refractive surgery candidates. The aim of this study was to determine the median CCT among normal Pakistani population and to correlate CCT with age, sex, and refractive errors.

Methods: We conducted a retrospective analysis of 5,171 healthy eyes in 2,598 patients who came to Hashmanis Hospital, Karachi, Pakistan. The age of the patients ranged from 6 to 70 years. The refractive error was gauged by an auto-refractometer, and CCT was measured using Oculus Pentacam ${ }^{\circledR}$.

Results: The median CCT of our study was $541.0 \mu \mathrm{m}$ with an interquartile range (IQR) of $44.0 \mu \mathrm{m}$. The median age was 26.0 years (IQR: 8.0). Median spherical equivalent (SE) of the patients was $-4.3 \mathrm{D}$ (IQR: 3.3 ) with the median sphere value as $-4.0 \mathrm{D}$ (IQR: 3.8). Lastly, the median cylinder was $-1.0 \mathrm{D}$ (IQR: 1.3 ). Age has a weak negative correlation with CCT $(r=-0.058)$ and shows statistical significance $(P<0.001)$. Additionally, males had thinner CCT readings than females $(P=0.001)$. The cylinder values, on the other hand, had a significant $(P=0.004)$ and positive correlation $(r=0.154)$. Three values showed no significant correlation: sphere $(P=0.100)$, SE $(P=0.782)$, and the left or right eye $(P=0.151)$.

Conclusion: Among the Pakistani population, CCT was significantly affected by three variables: sex, age, and cylinder. No relationship of CCT was observed with the left or right eye, sphere, and SE.

Keywords: refractive surgery, glaucoma, topography, sex, refractive errors, astigmatism

\section{Introduction}

Central corneal thickness (CCT) is a key indicator of corneal health status and helps to assess corneal diseases. The normal corneal thickness is about $540 \mu \mathrm{m}$ and mainly consists of the stroma, which is estimated at $450 \mu \mathrm{m}$ in the center. The stroma provides vital structural integrity and plays a key role in helping maintain transparency. ${ }^{1}$ It has been reported, however, that CCT follows a diurnal pattern being $10 \mu \mathrm{m}$ thicker in the morning due to reduced evaporation of water from underneath the closed eyelids. ${ }^{1,2}$

Usually, CCT is measured using a device known as the ultrasonic pachymeter. With recent advances, however, it is possible to measure this value using Oculus Pentacam $^{\circledR}$ (Pentacam HR; Oculus, Wetzlar, Germany), which maps the entire surface of the cornea. Additionally, it has been reported that CCT aids in estimating corneal barrier and endothelial pump function. ${ }^{3}$

CCT is a measure of corneal rigidity and has an impact on the accuracy of intraocular pressure (IOP) measurement by applanation tonometry. A greater resistance is offered by thicker corneas to the applanation tonometer, resulting in an artificially higher IOP reading. ${ }^{3-5}$ In addition, many studies have demonstrated that $\mathrm{CCT}$ is greater in
Correspondence: Nauman Hashmani Hashmanis Hospital, 68/B Khayaban-eShahbaz, DHA Phase 7, Karachi, Pakistan Tel +9232 I2828062

Email naumanhashmani@gmail.com (c) (1) (8) 2017 Hashmani et al. This work is published and licensed by Dove Medical Press limited. The full terms of this license are available at https://www.dovepress.com/terms.php (c) ${ }_{\mathrm{BY}} \mathrm{NC}$ and incorporate the Creative Commons Attribution - Non Commercial (unported, v3.0) License (http://creativecommons.org/licenses/by-nc/3.0/). By accessing the work you hereby accept the Terms. Non-commercial uses of the work are permitted without any further permission from Dove Medical Press Limited, provided the work is properly attributed. For permission for commercial use of this work, please see paragraphs 4.2 and 5 of our Terms (https://www.dovepress.com/terms.php). 
patients with ocular hypertension as compared to the general population. ${ }^{6-8}$ Furthermore, CCT is important in assessing eligibility in refractive surgery candidates where it is used to exclude those in danger of postoperative ectasia. ${ }^{9}$

CCT in the general population is associated with many demographic and ocular factors. Recent studies have shown that sex, race and/or ethnicity, and age may influence CCT. Specifically, it is found to be thinner in older individuals, Mongolians, and African-Americans than in whites. ${ }^{10-12}$ It was found that CCT of normotensive Nigerian adults reduces with increasing age and is not influenced by sex, corneal curvature, and corneal diameter. ${ }^{13}$ A German research showed a positive correlation with IOP, sex (men had thicker corneas), and spherical equivalent (SE), ${ }^{14}$ whereas an Iraqi research showed negative correlation between CCT and age, but it was not affected by sex. ${ }^{15}$

So far, two studies have already been conducted in Pakistan that examined the effect of age and ethnicity on CCT; however, these were limited in their sample size with $100^{16}$ and 1,000 patients, ${ }^{17}$ respectively. Additionally, the latter study only included adults and excluded those with refractive errors. We, therefore, wanted to study the effect of age, sex, and SE on CCT in a larger sample size of 5,171 eyes in the Pakistani population presenting to Hashmanis Hospital.

\section{Methods}

\section{Study design}

This was a retrospective analysis of 5,171 eyes in 2,598 patients who came to Hashmanis Hospital, Karachi, Pakistan. The study period lasted from January 2014 to December 2016. The study was approved by the Ethics Committee of Hashmanis Hospital, and informed consent was obtained for both inclusion in the study and for administration of the procedure.

\section{Inclusion and exclusion criteria}

All our patients underwent the routine eye examination: uncorrected visual acuity, best spectacle-corrected visual acuity, both cycloplegic and subjective refractive error, slit lamp examination, dilated retinal exam, keratometry, and Oculus Pentacam measurement.

Those with significant corneal pathology, such as scarring, edema, or dystrophy, were excluded. Additionally, those with a history of recent contact lens wear, ocular surgery, ocular trauma, glaucoma, or an IOP of greater than $22 \mathrm{mmHg}$ were excluded. Lastly, patients who had evidence of systemic disease or pregnancy were also excluded.

\section{Refraction}

We measured refraction using an auto-refractometer (KR-800; Topcon Medical Systems, Inc., Fukuoka, Japan). Each refraction measurement was in diopters (D) and had three values: sphere, cylinder, and SE. The SE was defined as the sum of the sphere value and half of the cylinder. Additionally, refractive outcomes were available in 4,915 eyes.

\section{Oculus Pentacam}

All patients underwent Oculus Pentacam measurement for the assessment of CCT. Every patient followed the same protocol during the scan. Their chin was positioned on the chin rest and, at the same time, their forehead was rested on the provided forehead strap. The patient was asked to stare at the blue fixation ring, while the examiner adjusted the focus and alignment of the machine. The machine marked the pupil at three points: the pupil edge, center, and corneal apex. Additionally, all patients were awake at least 1 hour prior to administration of the test. All scans were conducted between 10:00 AM and 4:00 PM.

This Pentacam system utilizes the blue light-emitting diode and a rotating Scheimpflug camera to take pictures of the anterior segment of the eye. At the time of study, the machine used Pentacam Software V1.20r87. We used the pachy apex value for CCT.

\section{Classifications}

First of all, we classified eyes into age groups by decades: 11-20, 21-30, 31-40, and 41-50 years. We had two different classifications for refractive outcomes. First, we divided each into a broad range of myopia ( $\mathrm{SE}<-0.25 \mathrm{D})$, emmetropia (SE -0.25 to $0.25 \mathrm{D}$ ), and hyperopia ( $\mathrm{SE}>0.25 \mathrm{D})$. Subsequently, we divided the myopic eyes into mild ( $\mathrm{SE}>-3 \mathrm{D})$, moderate ( $\mathrm{SE}-3$ to $-6 \mathrm{D})$, and severe myopia (SE $<-6 \mathrm{D})$. Likewise, we divided the hypermetropic eyes into mild (SE 0.25 to $3 \mathrm{D}$ ) and moderate hypermetropia $(\mathrm{SE}>3 \mathrm{D})$.

\section{Statistical analysis}

We used AppSheet software to collect data into Google sheets, which were then imported into the Statistical Package for the Social Sciences v23 software. All subsequent analyses were carried out using the program. We used descriptive statistics to calculate the median and interquartile ranges (IQR) all values; median values were used as the data were not normally distributed, as indicated by Shapiro-Wilk test. 
Subsequently, Mann-Whitney $U$ test was used to test for statistical significance between sexes and eyes. For all other variables, Pearson product-moment correlation was used. Lastly, the linear regression model was used for values that were statistically significant.

\section{Results \\ General characteristics}

We retrospectively analyzed the data for 5,171 eyes $(2,573$ left; 2,598 right) in 2,598 patients (1,596 males; 1,002 females) who came to Hashmanis Hospital for refractive surgery. The median CCT for this study was $541.0 \mu \mathrm{m}$ with an IQR of $44.0 \mu \mathrm{m}$. The median age was 26.0 years (IQR: 44.0). Median SE of the patients was $-4.3 \mathrm{D}$ (IQR: 3.3 ) with the median sphere value as $-4.0 \mathrm{D}$ (IQR: 3.8). Lastly, the median cylinder was $-1.0 \mathrm{D}$ (IQR: $1.3 \mathrm{D})$. This is shown in Table 1 along with the $P$-values and $r$-values.

\section{Correlation with age}

When analyzing the relationship of age with CCT, we divided our sample into four age groups: 11-20, 21-30, 31-40, and, 41-50 years. The median CCTs of these groups were found to be progressively falling, being $547.0 \mu \mathrm{m}$ (IQR: 49), $540.0 \mu \mathrm{m}$ (IQR: 45$), 537.0 \mu \mathrm{m}$ (IQR: 42), and $535.0 \mu \mathrm{m}$ (IQR: 39$)$, respectively $(P$-value $=0.001)$. Other age groups were excluded due to low sample size. This is shown in Table 2. Additionally, it can be seen that age is weakly but negatively correlated with CCT with an $r$-value of -0.058 . This relationship is shown in Figure 1.

\section{Association with sex}

The median CCT in male individuals was $538.0 \mu \mathrm{m}$ (IQR: 45), whereas in females it was $542.0 \mu \mathrm{m}$ (IQR: 44). Males had statistically significant thinner CCT readings than females $(P=0.001)$. This is shown in Table 3 .

\section{Correlation with spherical equivalent}

We found no statistical significance when correlating all refractive errors with $\mathrm{CCT}(P=0.782)$. The median CCT was $541.0 \mu \mathrm{m}$ (IQR: 44), $540.0 \mu \mathrm{m}$ (IQR: 50), and $542.0 \mu \mathrm{m}$ (IQR 43) in myopic, emmetropic, and hyperopic patients, respectively. We ran a separate analysis for these major classifications and found no significance among the three ( $P=0.587, P=0.906, P=0.606$, respectively).

When further sub-classified, those with severe myopia had a median CCT of $541 \mu \mathrm{m}$ (IQR: 47), those with moderate myopia had a median CCT of $541 \mu \mathrm{m}$ (IQR: 42), and those with mild myopia had a median CCT of $539 \mu \mathrm{m}$ (IQR: 49). Additionally, patients with mild hypermetropia had a median CCT of $542 \mu \mathrm{m}$ (IQR: 47) and those with severe hypermetropia had a median CCT of $544 \mu \mathrm{m}$ (IQR: 39). The relationship between SE and CCT had a weakly positive correlation ( $r=0.004)$ but did not reach statistical significance $(P=0.782)$. These data are shown in Table 3.

\section{Correlation with astigmatism}

The cylinder values had a positive correlation with CCT, with an $r$-value of 0.154 , and were found to be statistically significant $(P \leq 0.001)$. This relationship is shown in Figure 2.

\section{Discussion}

The median CCT found in our study was $541.0 \mu \mathrm{m}$ with IQR of $44.0 \mu \mathrm{m}$. Our results are similar when compared to the study performed by Channa et al, who found a mean CCT of $531.08 \mu \mathrm{m} .{ }^{16}$ However, another study performed in the country by Tayyab et al reported a significantly thinner mean CCT of $503.96 \mu \mathrm{m} .{ }^{17}$ The first study, like ours, was conducted in Karachi, which is at a far lower elevation when compared to Islamabad, which is the location of the latter study. This may explain the difference between the studies as it has been theorized that CCT is thinner in those who are

Table I General characteristics

\begin{tabular}{|c|c|c|c|c|c|c|}
\hline Characteristic & Total (median) & IQR & Min & Max & $P$-value & $r$-value \\
\hline Central corneal thickness, $\mu \mathrm{m}$ & 541.0 & 44.0 & 357.0 & 660.0 & & \\
\hline $\operatorname{Sex}(M ; F), n$ & 1,$596 ; 1,002$ & & & & 0.001 & N/A \\
\hline Eye (L; R), $n$ & 2,$573 ; 2,598$ & & & & 0.151 & N/A \\
\hline Age, years & 26.0 & 8.0 & 6.0 & 70.0 & $<0.001$ & -0.058 \\
\hline Spherical equivalent, D & -4.3 & 3.3 & -12.0 & 6.0 & 0.782 & 0.004 \\
\hline Sphere, D & -4.0 & 3.8 & -12.0 & 7.3 & 0.100 & -0.024 \\
\hline Cylinder, D & -1.0 & 1.3 & -9.3 & 5.0 & $<0.001$ & 0.154 \\
\hline
\end{tabular}

Abbreviations: IQR, interquartile range; Min, minimum; Max, maximum; M, male; F, female; N/A, not applicable; L, left; R, right. 
Table 2 Central corneal thickness by age groups

\begin{tabular}{llllll}
\hline $\begin{array}{l}\text { Age group } \\
\text { (years) }\end{array}$ & N & Median & IQR & Min & Max \\
\hline$I I-20$ & $80 I$ & 547.0 & 49.0 & 370.0 & 643.0 \\
$2 I-30$ & $3, I 0 I$ & 540.0 & 45.0 & 357.0 & 660.0 \\
$3 I-40$ & 998 & 537.0 & 42.0 & $36 I .0$ & 650.0 \\
$4 I-50$ & $2 I 2$ & 535.0 & 39.0 & 376.0 & $6 I 3.0$
\end{tabular}

Note: Other age groups were excluded due to low sample size.

Abbreviations: IQR, interquartile range; Min, minimum; Max, maximum

at a higher altitude; however, the mechanism of this effect is yet to be understood. ${ }^{18}$

Age is an important factor that affects corneal measurements. In our sample, age had a statistically significant and weak negative correlation with the median CCT reading $(P<0.001, r=-0.058)$. Tayyab et al agree with our finding and found a decrease of $0.12 \mu \mathrm{m}$ in CCT per year. ${ }^{17}$ Other studies around the globe had similar results. For example, a research in Tehran concluded that volunteers younger than 20 years had thicker corneas when compared to those who were older. ${ }^{19}$ The sub-Saharan study also showed that CCT values decreased significantly with older age $(P=0.002) .{ }^{20}$ However, not all studies agree, with one study in a large population in the USA showing no association of CCT with age. ${ }^{21}$

In our study, we showed that men had significantly thinner corneas than females $(P=0.001)$ with a median CCT of $538 \mu \mathrm{m}$ and $542 \mu \mathrm{m}$, respectively. Another study carried out in Kara$\mathrm{chi}^{16}$ did not find a significant relationship of CCT with variables like age, sex, or presence of comorbidity. Conversely, in Japanese, African, and Chinese studies, it was found that men had thicker CCTs. ${ }^{20,22,23} \mathrm{CCT}$ has been said to have a diurnal

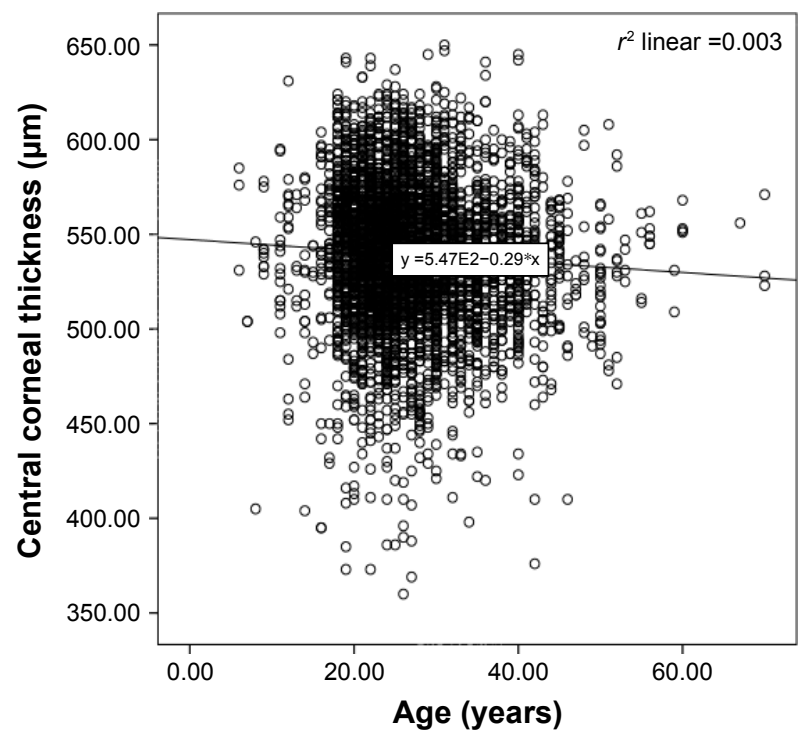

Figure I Correlation of central corneal thickness with age.
Table 3 Central corneal thickness by sex

\begin{tabular}{llllll}
\hline Sex & N & Median & IQR & Min & Max \\
\hline Male $^{\#}$ & 3,188 & 538.0 & 45.0 & 361.0 & 660.0 \\
Female $^{\#}$ & I,983 & 542.0 & 44.0 & 357.0 & 650.0 \\
\hline
\end{tabular}

Note: \#Number of eyes.

Abbreviations: IQR, interquartile range; Min, minimum; Max, maximum.

variation in thickness. ${ }^{24}$ Additionally, CCT in females has been linked to additional variables such as oral contraceptive pill (OCP) use ${ }^{25}$ and menstrual cycle. ${ }^{26}$ Perhaps, these factors could explain the discrepancy between our data and that of the global community, as we did not account for these.

We found astigmatism to have a significant positive correlation with CCT $(P<0.001, r=0.154)$. A few papers have looked at this relationship previously. For example, one paper found a thicker CCT in patients with against the rule astigmatism. ${ }^{27}$ Another study tried to find the relationship between CCT and surgically induced astigmatism. The study found a negative correlation postoperatively that was lost after 2 months. ${ }^{28}$ We recommend further investigation into this relationship.

The SE in our research did not seem to have a significant correlation with CCT ( $P=0.782)$. Also, there was a negative but insignificant correlation between sphere component and CCT ( $P=0.100, r=-0.024)$. A similar research was conducted in China and no relationship was found between the SE and the CCT, as in our study. ${ }^{29}$ Conversely, a study in Iraqi people found a statistically significant positive correlation with the same variables. ${ }^{15}$ As shown in Table 4, the thickest corneas appear at the end of the two refractive spectrums: severe

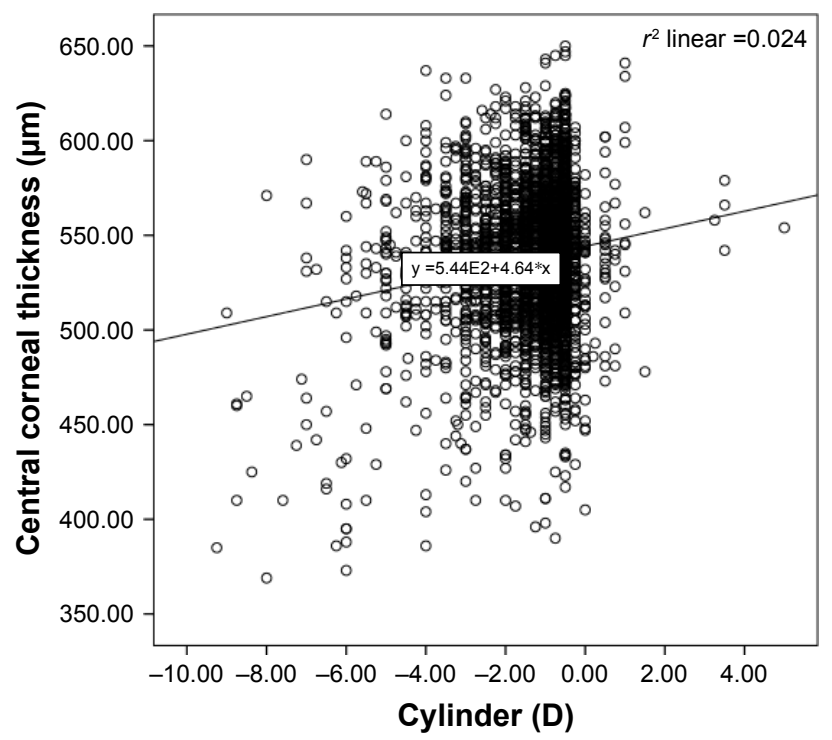

Figure 2 Correlation of central corneal thickness with cylinder. 
Table 4 Central corneal thickness divided by refractive classifications

\begin{tabular}{|c|c|c|c|c|c|c|c|}
\hline Refractive classification & $\mathbf{N}$ & Median & IQR & Min & $\operatorname{Max}$ & P-value & r-value \\
\hline All classifications & 4,915 & 541.0 & 44.0 & 357.0 & 660.0 & 0.782 & 0.004 \\
\hline Myоріа & 4,683 & 541.0 & 44.0 & 360.0 & 650.0 & 0.587 & -0.008 \\
\hline Emmetropia & 48 & 540.0 & 50.0 & 416.0 & 610.0 & 0.906 & 0.018 \\
\hline Hyperopia & 184 & 542.0 & 43.0 & 398.0 & 643.0 & 0.606 & 0.038 \\
\hline \multicolumn{8}{|l|}{ Sub-classification } \\
\hline Severe myopia & 1,166 & 541.0 & 47.0 & 360.0 & 645.0 & & \\
\hline Moderate myopia & 2,456 & 541.0 & 42.0 & 373.0 & 650.0 & & \\
\hline Mild myopia & $1,06 \mid$ & 539.0 & 49.0 & 386.0 & 643.0 & & \\
\hline Emmetropia & 48 & 540.0 & 50.0 & 416.0 & 610.0 & & \\
\hline Mild hypermetropia & 110 & 542.0 & 47.0 & 398.0 & 614.0 & & \\
\hline Moderate hypermetropia & 74 & 544.0 & 39.0 & 417.0 & 643.0 & & \\
\hline
\end{tabular}

Note: Refractive outcomes were available for 4,915 eyes.

Abbreviations: IQR, interquartile range; Min, minimum; Max, maximum.

myopia and moderate hypermetropia. We, therefore, suspected that a separate analysis of the three classifications would yield a significant correlation. However, this was not found to be the case.

Several limitations must be kept in mind while reading this paper. Firstly, this is a retrospective study and, therefore, all associated limitations must be considered. Secondly, since this study was conducted in a single city, the effects of the environment could not be assessed. Lastly, factors affecting the female CCT, like the menstrual cycle and OCP use, were not known.

\section{Conclusion}

The median CCT in Pakistani population was $541.0 \mu \mathrm{m}$. CCT was significantly affected by three variables: sex, age, and cylinder. No relationship of CCT was seen with the left or right eye, sphere, and SE.

\section{Acknowledgment}

The research was funded by Hashmanis Foundation.

\section{Disclosure}

Dr Nauman Hashmani is the son of Dr Sharif Hashmani.

Dr Misbahul Aziz is the chairman of the Ethics Committee at Hashmanis Hospital. The authors report no other conflicts of interest in this work.

\section{References}

1. Tasman W, Jaeger EA. Ophthalmology. 13th ed. Philadelphia: Lippincott Williams \& Wilkins; 2012.

2. Yanoff M, Duker JS. In: Ayad AF, Matthew VB, Soong HK, Mohsin A, Ramos-Esteban JC, Katz LJ, editors. Ophthalmology. China: Elsevier Saunders; 2014.

3. Ehlers N, Bramsen T, Sperling S. Applanation tonometry and central corneal thickness. Acta Ophthalmol (Copenh). 1975;53(1):34-43.

4. Herndon LW, Choudhri SA, Cox T, Damji KF, Shields MB, Allingham RR. Central corneal thickness in normal, glaucomatous, and ocular hypertensive eyes. Arch Ophthalmol. 1997;115(9):1137-1141.
5. Orssengo GJ, Pye DC. Determination of the true intraocular pressure and modulus of elasticity the human cornea in vivo. Bull Math Biol. 1999; 61(3):551-572.

6. Brandt JD, Beiser JA, Kass MA, Gordon MO. Central corneal thickness in the Ocular Hypertension Treatment Study (OHTS). Ophthalmology. 2001;108(10):1779-1788.

7. Herman DC, Hodge DO, Bourne WM. Increased corneal thickness in patients with ocular hypertension. Arch Ophthalmol. 2001;119(3): 334-336.

8. Argus WA. Ocular hypertension and central corneal thickness. Opthalmology. 1995;102(12):1810-1812.

9. Hashemi H, Mehravaran S. Central corneal thickness measurement with Pentacam, Orbscan II, and ultrasound devices before and after laser refractive surgery for myopia. J Cataract Refract Surg. 2007; 33(10):1701-1707.

10. Wolfs RC, KlaverCC, Vingerling JR, Grobbee DE, Hofman A, de Jong PT. Distribution of central corneal thickness and its association with intraocular pressure. The Rotterdam Study. Am J Ophthalmol. 1997; 123(6):767-772.

11. Foster PJ, Baasanhu J, Alsbirk PH, Munkhbayar D, Uranchimeg D, Johnson GJ. Central corneal thickness and intraocular pressure in a Mongolian population. Ophthalmology. 1998;105(6):969-973.

12. Faragher RG, Mulholland B, Tuft SJ, Sandeman S, Khaw PT. Aging and the cornea. Br J Ophthalmol. 1997;81(10):814-817.

13. Iyamu E, Osuobeni E. Age, gender, corneal diameter, corneal curvature, and central corneal thickness in Nigerians with normal intra ocular pressure. J Optom. 2012;5(2):87-97.

14. Hoffmann EM, Lamparter J, Mirshahi A, et al. Distribution of central corneal thickness and its association with ocular parameters in a large central European cohort: the Gutenberg health study. PLoS One. 2013; 8(8):e66158.

15. Kadhim YJ, Farhood QK. Central corneal thickness of Iraqi population in relation to age, gender, refractive errors, and corneal curvature: a hospital-based cross-sectional study. Clin Ophthalmol. 2016;10: 2369-2376.

16. Channa R, Mir F, Shah MN, Ali A, Ahmad K. Central corneal thickness of Pakistani adults. J Pak Med Assoc. 2009;59(4):225-228.

17. Tayyab A, Masrur A, Afzal F, Iqbal F, Naseem K. Central corneal thickness and its relationship to intra-ocular and epidemiological determinants. J Coll Physicians Surg Pak. 2016;26(6):494-497.

18. Patyal S, Arora A, Yadav A, Sharma VK. Corneal thickness in highlanders. High Alt Med Biol. 2017;18(1):56-60.

19. Hashemi H, Yazdani K, Mehravaran S, et al. Corneal thickness in a population-based, cross-sectional study: the Tehran Eye Study. Cornea. 2009;28(4):395-400.

20. Mercieca K, Odogu V, Fiebai B, Arowolo O, Chukwuka F. Comparing central corneal thickness in a sub-Saharan cohort to African Americans and Afro-Caribbeans. Cornea. 2007;26(5):557-560. 
21. Prasad A, Fry K, Hersh PS. Relationship of age and refraction to central corneal thickness. Cornea. 2011;30(5):553-555.

22. Wang Q, Liu W, Wu Y, Ma Y, Zhao G. Central corneal thickness and its relationship to ocular parameters in young adult myopic eyes. Clin Exp Optom. 2017;100(3):250-254.

23. Nomura H, Ando F, Niino N, Shimokata H, Miyake Y. The relationship between age and intraocular pressure in a Japanese population: the influence of central corneal thickness. Curr Eye Res. 2002;24(2):81-85.

24. Harper CL, Boulton ME, Bennet D, et al. Diurnal variations in human corneal thickness. Br J Ophthalmol. 1996;80(12):1068-1072.

25. Kurtul BE, Inal B, Ozer PA, Kabatas EU. Impact of oral contraceptive pills on central corneal thickness in young women. Indian J Pharmacol. 2016;48(6):665-668.
26. Giuffrè G, Di Rosa L, Fiorino F, Bubella DM, Lodato G. Variations in central corneal thickness during the menstrual cycle in women. Cornea. 2007;26(2):144-146.

27. Turkey H, Bostanci C, Toklu Y. Relationship between Type of Astigmatism and Central Corneal Thickness. Milan: European Society of Cataract and Refractive Surgeons; 2012.

28. Woo SJ, Lee JH. Effect of central corneal thickness on surgically induced astigmatism in cataract surgery. $J$ Cataract Refract Surg. 2003;29(1): 2401-2406.

29. Oliveira C, Tello C, Ritch R, Liebmann JM. Correlation between central corneal thickness, scleral thickness and refractive error. Invest Ophthalmol Vis Sci. 2004;45(13):963.
Clinical Ophthalmology

\section{Publish your work in this journal}

Clinical Ophthalmology is an international, peer-reviewed journal covering all subspecialties within ophthalmology. Key topics include: Optometry; Visual science; Pharmacology and drug therapy in eye diseases; Basic Sciences; Primary and Secondary eye care; Patient Safety and Quality of Care Improvements. This journal is indexed on

\section{Dovepress}

PubMed Central and CAS, and is the official journal of The Society of Clinical Ophthalmology (SCO). The manuscript management system is completely online and includes a very quick and fair peer-review system, which is all easy to use. Visit http://www.dovepress.com/ testimonials.php to read real quotes from published authors. 